Plant Tissue Cult. \& Biotech. 31(2): 115-122, 2021 (December)

DOI: https://doi.org/10.3329/ptcb.v31i2.57339

CBangladesh Assoc. for Plant Tissue Culture \& Biotechnology
ISSN 1817-3721, E-ISSN 1818-8745

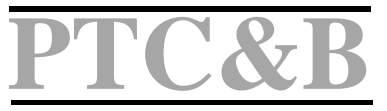

\title{
Characterization of Multiple Grain Rice (Oryza sativa L.) Biramsundari from Bangladesh
}

\author{
Rita Sarah Borna, S. Mitra, A. J. A. Gifary and R. H. Sarker* \\ Plant Breeding and Biotechnology Laboratory, Department of Botany, University of Dhaka, \\ Dhaka-1000, Bangladesh
}

Key words: Rice, multiple grain, CpSSR, Biramsundari

\begin{abstract}
Biramsundari is a rice germplasm from Bangladesh showing one to four grain in a single seed. Comparative study of morphological traits revealed that BS is a taller rice variety compared to modern rice varieties with longer and wider flag leaves, longer panicle length and higher thousand seed weight (TSW) than transplanted aman rice variety BRRI dhan 49. Flower morphological analysis unveil that multiple grains of Biramsundari are originating from multiple number of carpels in each floret. About $40.1 \%$ flower contains three carpels. Fluorescent microscopic study also confirms the zygotic origin of multiple grain formation in Biramsundari. Molecular characterisation of Biramsundari was performed by using TeaCpSSR27 and TeaCpSSR28 chloroplast microsatellite markers. The results of this investigation reveal that atpF and $r s p 14-p s a B$ intergenic spacer regions of Biramsundari have variation compared to sequences of with $O$. sativa ssp. indica, $O$. sativa ssp. japonica and O. rufipogon.
\end{abstract}

\section{Introduction}

Rice (Oryza sativa L.) is one of the most important staple food crops for human consumption. The genus Oryza comprises 23 species (Vaughan et al. 2003), among them only two species, $O$. sativa L. and O. glaberrima Steud. are cultivated for human consumption. Indica and japonica are two sub species of $O$. sativa. Approximately $70 \%$ of the total rice producing area is cultivated using indica, mainly in South Asia, Southeast Asia and Southern China (Huang et al.2012). About 50 percent of the world's population derives most of their calories from rice. Almost 90 percent of the population of Bangladesh, Myanmar, Sri Lanka, Vietnam and Kampuchea consume rice at least two times a day. Considering the largest world population depending on rice, it is necessary to develop rice varieties with high yielding potentials for the future.

*Author for correspondence: <rhsarker2000@yahoo.co.uk>. 
The inflorescence is the major trait that determines yield in rice (Gao et al. 2015). Unlike other grasses, rice has a unique floral structure. The spikelet is the key unit of grass inflorescence, it comprises a floret, a pair of empty glumes and a pair of highly reduced glumes called rudimentary glumes. The floret consists of a pair of lemma and palea, lodicules, 6 stamens and a carpel (Yoshida and Nagato 2011). Biramsundari is a natural rice germplasm of Bangladesh, contains multiple carpels, resulting multiple grains after fertilization, in a single spikelet. This highly promising trait opens the possibility of obtaining new rice varieties with higher yield potential for the future. In this investigation, the morphological characters of Biramsundari were compared with that of the rice cultivar BRRI dhan 49.

So, far very limited information is available about natural rice germplasm with multiple carpel or grain number. However, in few cases, mutations can cause changes in number of embryos, carpels and grains in rice. Ximei et al. (2006) has reported a polyembryonic mutant of autotetraploid rice induced by $\mathrm{N}+$ beam implantation where adventitious embryos were originated from antipodal cells. Puri et al. (2010) reported that loss of function of polyembryo gene OsPE can causes multiple embryos in rice. Loss of function of Arabidopsis CLAVATA orthologue FLORAL ORGAN NUMBER1 and TWIN GRAIN1/FON2/FON4 can also increase carpel and grain number in rice (Moon et al. 2006, Ye et al. 2017). In this study, we performed floral phenotypic analysis and pollen pistil interactions to reveal the nature of embryo formation in Biramsundari.

For molecular characterisation of Biramsundari, chloroplast simple sequences repeat (cpSSRs) markers from chloroplast microsatellite regions was utilized. The cPSSR markers are well known to identify genetic variation. Powell et al. (1995), first developed cpSSRs as genetic marker and showed that due to high polymorphism and co-dominant inheritance, cpSSRs have high efficiency to identify variation among varieties. Diekmann et al. (2012)-developed nine new cpSSR markers and showed that TeaCpSSR28 was able to distinguish between all Lolium species and TeaCpSSR27 can detect variation among some L. perenne accessions. Here, we have used TeaCpSSR27 and TeaCpSSR28 markers to show the chloroplast genome variability in Biramsundari in compare with O. sativa ssp. indica, O. sativa ssp. japonica and O. rufipogon.

\section{Materials and Methods}

Mature seeds of Biramsundari (BS) were collected from the local farmers of Dinajpur, Bangladesh. Seeds of the rice variety BRRI dhan 49 were collected from Bangladesh Rice Research Institute (BRRI). Plants of Biramsundari and BRRI dhan 49 were raised and studied in the field of Botanical Garden, University of Dhaka.

A comparative analysis of the morphological characteristics of the Biramsundari and BRRI dhan 49 was carried out. All the data were collected from mature plants following initiation of flowers. For flower phenotypic analysis, spikelets were collected randomly and floral parts are dissected and analyzed under fluorescent microscope. Statistical analysis was done by using Microsoft Excel 2016. 
Pollen-pistil interaction and the ovules were observed under fluorescent microscope. For this purpose spikelets were first hydrolyzed in $1 \mathrm{~N} \mathrm{NaOH}$ at $60^{\circ} \mathrm{C}$ for $15 \mathrm{~min}$ then mounted with fluorescent dye $0.1 \%$ decolorized aniline blue solution following the method described by Sarker et al. (1997). Pollen tube development following selfpollination was observed under fluorescent microscope with UV illumination. For pollen fertility analysis, excised anthers were placed on a glass slide with a drop of aniline blue solution and tap a bit using forceps to make the pollen grains spread uniformly, covered under a coverslip and then examined using the fluorescent microscope.

Fresh leaves of Biramsundari were collected from the field grown plants and total genomic DNA was extracted by following CTAB method (Doyle and Doyle 1987, 1990). atpF intron and rsp14-psaB region of chloroplast genome was amplified by PCR, using the primers TeaCpSSR27 and TeaCpSSR28 (Diiekmann et al. 2012). The PCR reactions were performed in a volume of $25 \mu \mathrm{L}$ of mix containing $2.5 \mu \mathrm{l} 10 \times$ PCR buffer, $2 \mathrm{mM}$ $\mathrm{MgCl}_{2}, 2 \mathrm{mM}$ dNTPs, $1 \mu \mathrm{M}$ of each primer, 1.25U of Taq polymerase (Invitrogen) and 50 ng DNA. The PCR conditions were $95^{\circ} \mathrm{C}$ for $4 \mathrm{~min}$ followed by 30 cycles of $94^{\circ} \mathrm{C}$ for 1 $\mathrm{min}, 50^{\circ} \mathrm{C}$ for $1 \mathrm{~min}$ for annealing, and finally $72^{\circ} \mathrm{C}$ for $10 \mathrm{~min}$ for elongation. Purified PCR amplified DNA were then subjected for automated sequencing in one direction. TeaCpSSR27 forward and TeaCpSSR28 forward primers were used for sequencing. BLAST similarity searches were performed using NCBI BLASTn. Published sequence of atpF intron and rsp14-psaB regions of $O$. sativa indica, O. sativa japonica and O. rufipogon were collected from NCBI and then sequence alignment was done by using MUSCHEL software (Edgar 2004) with the sequences obtained in this study.

\section{Results and Discussion}

Morphological studies of Biramsundari were performed in plants grown in the field. To compare different morphological parameters, another Aman rice BRRI dhan 49 (Oryza sativa sub spp. indica) was planted side by side with BS.

Morphological analysis showed that the average plant height of Biramsundari and BRRI dhan 49 was approximately $167.87 \mathrm{~cm}$ and $99.14 \mathrm{~cm}$, respectively at maturity. Though rice plant height can varies from $50 \mathrm{~cm}$ to $500 \mathrm{~cm}$ (GRiSP 2013), Biramsundari can be considered as a taller rice variety. Average numbers of tiller after the initiation of first panicle were 6.0 for Biramsundari and 8.0 for BRRI dhan 49. At maturity, flag leaf length and breadth were $49.07 \pm 12.27 \mathrm{~cm}$ and $1.55 \pm 0.21 \mathrm{~cm}, 35.75 \pm 9.8$ and $1.28 \pm 0.2 \mathrm{~cm}$ for Biramsundari and BRRI dhan 49, respectively. Panicle length was also higher in Biramsundari $(26.92 \pm 4.25)$ then BRRI dhan 49 (15.38 \pm 3.9$)$. Interestingly it was observed that each spikelet of BS contains one to four grains $(32.35,52.94,14.12$ and $0.58 \%$ spikelets contain one, two, three and four grains, respectively) whereas BRRI dhan 49 has one grain/spikelet like ideal rice plants. Thousand seed weight was $27.42 \mathrm{gm}$ for Biramsundari and 14.35 for BRRI dhan 49 (Table 1 and Fig. 1). 
Table 1. Morphology and yield analysis of Biramsundari and BRRI dhan 49 ( $\mathbf{N}=$ number of samples).

\begin{tabular}{|l|l|l|}
\hline Agronomic traits & Biramsundari & BRRI dhan 49 \\
\hline Plant height $(\mathrm{cm})$ & $167.87 \pm 30.11(\mathrm{~N}=14)$ & $99.14 \pm 18.47(\mathrm{~N}=16)$ \\
\hline No. of tiller & $6.0 \pm 1.7(\mathrm{~N}=14)$ & $8.0 \pm 2.05(\mathrm{~N}=15)$ \\
\hline Flag leaf length $(\mathrm{cm})$ & $49.07 \pm 12.27(\mathrm{~N}=20)$ & $35.75 \pm 9.8(\mathrm{~N}=20)$ \\
\hline Flag leaf breadth $(\mathrm{cm})$ & $1.55 \pm 0.21(\mathrm{~N}=20)$ & $1.28 \pm 0.2(\mathrm{~N}=20)$ \\
\hline Panicle length $(\mathrm{cm})$ & $26.92 \pm 4.2526 .92 \pm 4.25(\mathrm{~N}=64)$ & $15.38 \pm 3.9(\mathrm{~N}=63)$ \\
\hline No. of grain per spikelet & $\begin{array}{l}1-4(\text { one }=32.35 \%, \text { two }=52.94 \%, \\
\text { three }=14.12 \% \text { and four }=0.58 \%)\end{array}$ & 1.0 \\
\hline TSW $(\mathrm{gm})$ & 27.42 & 14.35 \\
\hline
\end{tabular}
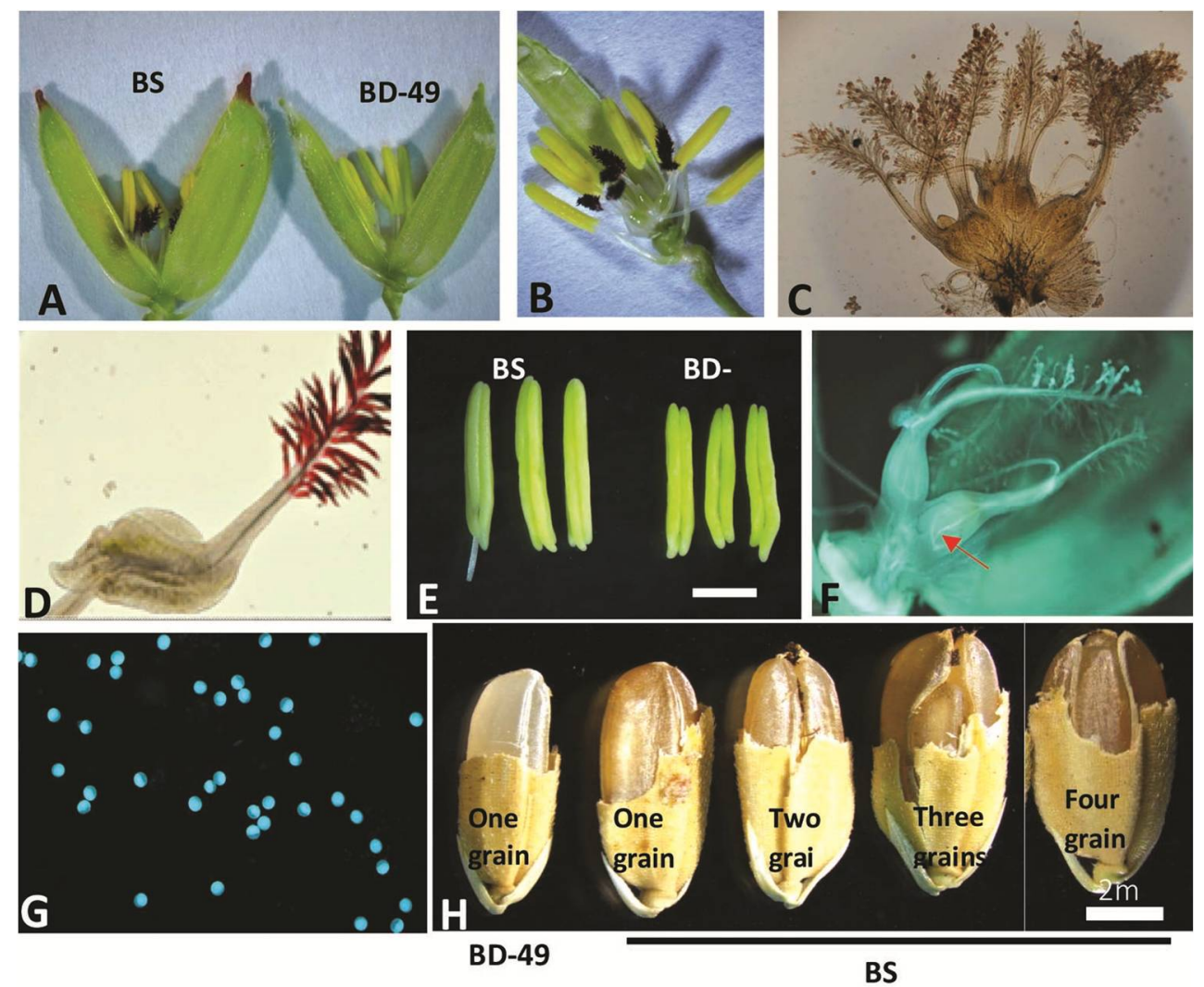

Fig. 1. Floral morphology and fertility analysis of Biramsundari, A) Open spikelet of Biramsundari and BRRI dhan 49, B and C) Dissected spikelets of Biramsundari showing multiple carpels and stigma, D) Anther originated stigma of Biramsundari, E) Anthers of Biramsundari and BRRI dhan 49 (Bar-1mm), F) Pollen pistil interaction of BS showing the pollen tube growth up to the ovule in the carpel (red arrow), G) Fertile pollen grains of Biramsundari and H) Seeds of Biramsundari and BRRI dhan 49. 
During dissection analysis of spikelet, it was observed that number of carpels in each spikelet varied from one to six, whereas ideal rice flower contains only one carpel. Highest, $40.1 \%$ flowers contain three carpels. Stigma colour was purple. Anther number also varied from five to seven. Anther length was approximately $2.4 \mathrm{~mm}$ which was within the range of normal anther length of rice (Raghavan 1988). About 17\% flower contains anther originated stigma. This type of homeotic conversion of anther in to stigma usually caused by dis-regulation of genes associated with floral organ development (Suzaki et al. 2004 and Song et al. 2017). Spikelets bear purple awn on the tip of lemma (Table 2 and Fig. 1).

From flower morphological analysis it was observed that each spikelet contains one to six carpels but at maturity one to four grains were found, which suggests that all the carpels were not producing grains after fertilization. Therefore, pollen pistil interaction was performed to understand the process of multiple grain formation in Biramsundari. Pollens were successfully germinated on the pistil and pollen tube growth was observed up to the ovule. This observation suggests that the multiple grain formation in Biramsundari might be zygotic in origin (Fig. 1F). Pollen fertility was found $88.29 \%$. Previously, Ximei et al. (2006) and Puri et al. (2010) reported polyembryonic rice caused by gene mutation. Moon et al. (2006) and Ye et al. (2017) reported that mutation in FLORAL ORGAN NUMBER1 and TWIN GRAIN1/FON2/FON4 can increase carpel and grain number in rice spikelet. More study needed to unveil the molecular mechanisms underlying the multiple grain formation in Biramsundari.

Table 2. Floral morphology of Biramsundari (BS) and BD-49.

\begin{tabular}{|c|c|c|}
\hline Floral traits & Biramsundari (BS) & BRRI dhan 49 \\
\hline No. of carpel per floret & $\begin{array}{l}1-6(\text { one }=3.1 \%, \text { two }=6.9 \%, \text { Three }=40.1 \%, \\
\text { four }=36.2 \% \text {, five }=10.3 \% \text { and six }=3.4 \%)\end{array}$ & 1 \\
\hline Stigma colour & Purple & White \\
\hline No. of anther & $5-7($ five $=21.05 \%$, six $=73.68 \%$, seven $=5.2 \%)$ & $\operatorname{six}$ \\
\hline Anther originated pistle & $17.89 \%$ & 0.0 \\
\hline Own & Purple own present & Absent \\
\hline
\end{tabular}

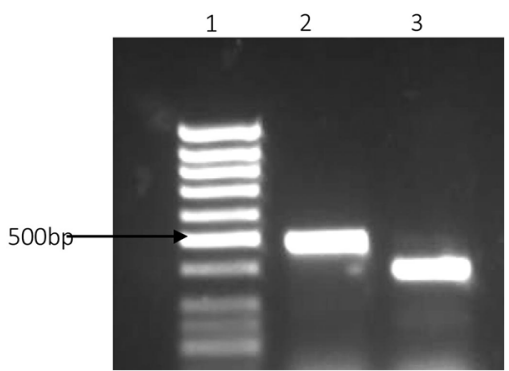

Fig. 2. PCR amplification of amplify atpF intron and $r s p 14-p s a B$ inter genic regions by using TeaCpSSR27 (Lane 2) and TeaCpSSR28 markers (Lane 3). $1 \mathrm{~kb}$ DNA ladder (Lane 1). 


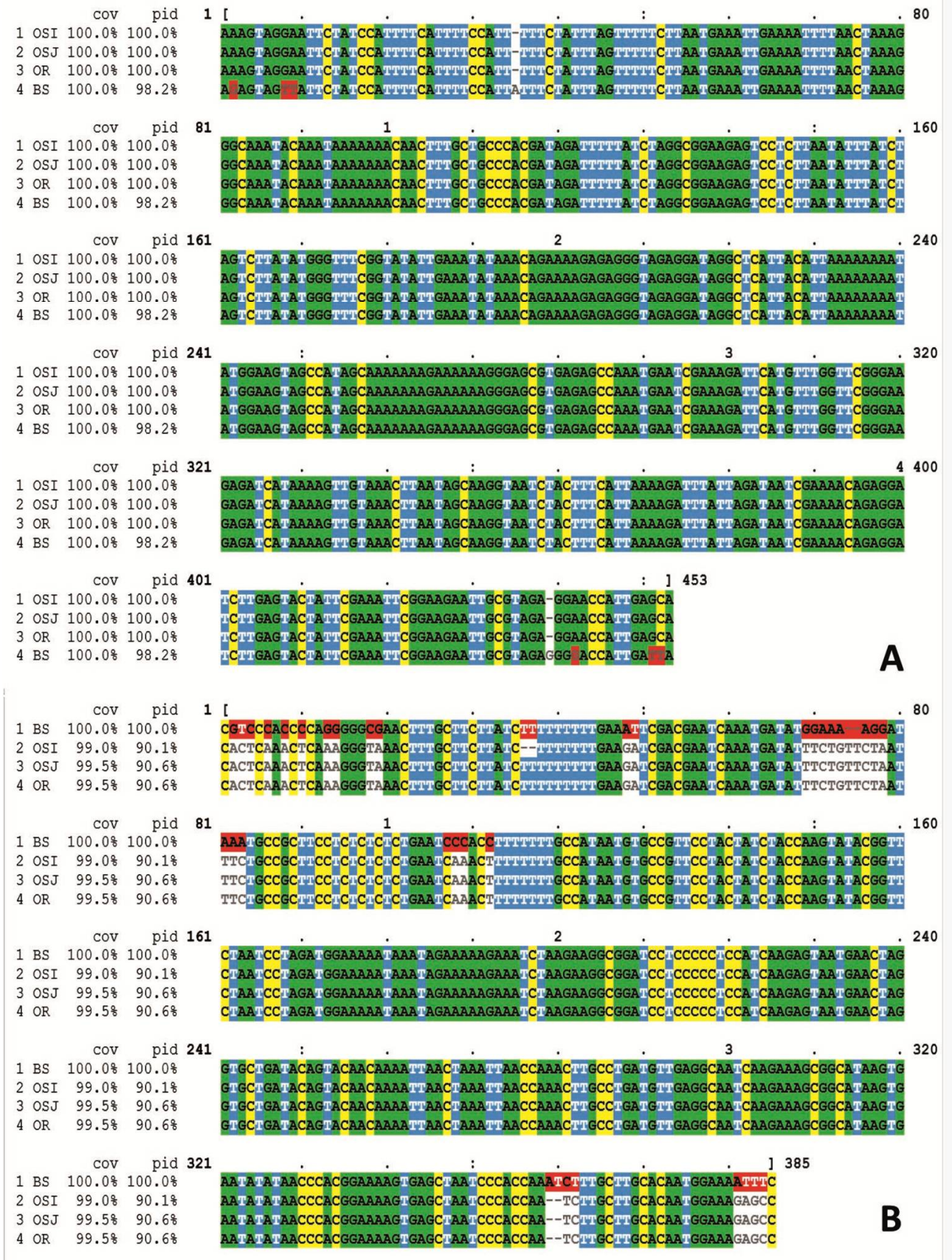

Fig. 3. DNA sequence alignment diagram for A) atpF and B) rsp14-psaB intergenic region of the chloroplast genome of Biramsundari, OSI (O. sativa indica), OSJ (O. sativa japonica) and OR $(O$. rufipogon). The alignment was obtained by using MUSCHEL software. Red shading indicates polymorphic nucleotides (i.e., SNPs). 
During this study, TeaCpSSR27 and TeaCpSSR28 cpSSR markers amplifying atpF intron and rsp14-psaB intergenic regions of chloroplast DNA respectively, were used to identify genetic variation in Biramsundari. TeaCpSSR27 and TeaCpSSR28 cpSSR markers were able to amplify $484 \mathrm{bp}$ and $383 \mathrm{bp}$ bands respectively from the genomic DNA of Biramsundari (Fig. 2). Purified PCR products were subjected to Sanger sequencing. Sequences were confirmed through BLAST analysis and aligned with published sequence of $a t p F$ intron and $r s p 14-p s a B$ regions of $O$. sativa indica, $O$. sativa japonica and $O$. rufipogon. From the alignment, repeated nucleotide motifs were identified in both atpF intron and rsp14-psaB intergenic region of Biramsundari. In case of atpF intron region, out of 453 bases aligned, 8 SNPs were observed. Whereas, in case of $r s p 14 p s a B$ region, out of 385 bases, 39 bases (10.18\%) represent SNPs (Fig. 3). Therefore, DNA sequence alignment diagram revealed that sequences of both atpF intron and rsp14-psaB intergenic region of Biramsundari have variation in compare with that of Oryza sativa indica, Oryza sativa japonica and Oryza rufipogon. This result suggests TeaCpSSR27 and TeaCpSSR28 as potential molecular marker for Biramsundari. Previously, Diekmann et al. (2012) reported TeaCpSSR27 and TeaCpSSR28 microsatellite markers to assess genetic diversity of grass species and showed that those markers can detect variation at interspecific level.

In this investigation various morphological characters of Biramsundari were compared with BRRI dhan 49. Most of the agronomically important characteristics of Biramsundari were found to be better than that of BRRI dhan 49. Higher yield in Biramsundari is believed to be due to the occurrence of multiple numbers of grains in one seed. Further it was that clear that the grains obtained in Biramsundari were zygotic in nature. It is suggested that TeaCpSSR27 and TeaCpSSR28 can be considered as a suitable molecular marker for Biramsundari.

\section{Acknowledgements}

Authors are grateful to Dr. Tahmina Islam and Professor Dr. Mohammad Nurul Islam for their suggestions and cooperation during the preparation of this manuscript. The authors are also thankful to BRRI authorities for providing BRRI dhan 49 seeds for this investigation.

\section{References}

Diekmann K, Hodkinson TR and Barth S (2012) New chloroplast microsatellite markers suitable for assessing genetic diversity of Lolium perenne and other related grass species. Annals of Botany 110: 1327-1339.

Doyle JJ and Doyle JL (1987) A rapid DNA isolation procedure for small quantities of fresh leaf tissue. Phytochem. Bull. 19: 11-15.

Doyle JJ and Doyle JL (1990) Isolation of plant DNA from fresh tissue. Focus 12:13-15.

Edgar RC (2004) MUSCLE: a multiple sequence alignment method with reduced time and space complexity. BMC Bioinformatics 5: 113. 
Gao F, Wang K, Liu Y, Chen Y, Chen P, Shi Z, Luo J, Jiang D, Fan F, Zhu Y and Li S (2015) Blocking miR396 increases rice yield by shaping inflorescence architecture. Nature Plants 2: 15196.

GRiSP (Global Rice Science Partnership) (2013) Rice almanac, 4th edition. Los Baños (Philippines): International Rice Research Institute. 283 p.

Huang X, Kurata N, Wei X, Wang Z-X, Wang A, Zhao Q, Zhao Y, Liu K, Lu, H, Li W, Guo Y, Lu Y, Zhou C, Fan D, Weng Q, Zhu C, Huang T, Zhang L, Wang Y, Feng L, Furuumi H, Kubo T, Miyabayashi T, Yuan X, Xu Q, Dong G, Zhan Q, Li C, Fujiyama A, Toyoda A, Lu T, Feng Q, Qian Q, Li J and Han B (2012) A map of rice genome variation reveals the origin of cultivated rice. Nature 490: 497-501.

Moon S, Jung K, Lee D, Lee D, Lee J, An K, Kang H and An G (2006) The rice FON1 gene controls vegetative and reproductive development by regulating shoot apical meristem size. Molecules and Cells 21(1): 147-52.

Powell W, Morgante M, McDevitt R, Vendramin G and Rafalski J (1995) Polymorphic simple sequence repeat regions in chloroplast genomes: Applications to the population genetics of pines. Proceedings of the National Academy of Sciences of the United States of America 92: 7759-7763.

Puri A, Basha PO, Kumar M, Rajpurohit D, Randhawa GS, Kianian SF, Rishi A and Dhaliwal HS (2010) The polyembryo gene (OsPE) in rice. Funct. Integr. Genomics 10(3): 359-366.

Raghavan V (1988) Anther and pollen development in rice (Oryza sativa). Am. J. Bot. 75: 183-196.

Sarker RH, Paul SK, Haque AKMK and Hoque MI (1997) Pollen tube growth and variation in pollen tube callose plugs in some Corchorus species. Phytomorphology 47(3): 311-317.

Song S, Li L, Li Y, Wang T and Fu X (2017) Overexpression of gene OsSUI1 affects floral organ development in rice (Oryza sativa L.). Mol Breeding 38, 4

Suzaki T, Sato M, Ashikari M, Miyoshi M, Nagato Y, Hirano H (2004) The gene FLORAL ORGAN NUMBER1 regulates floral meristem size in rice and encodes a leucine-rich repeat receptor kinase orthologous to Arabidopsis CLAVATA1. Development 131 (22): 5649-5657.

Vaughan DA, Morishimay H and Kadowaki K (2003) Diversity in the Oryza genus. Curr. Opin. Plant Biol. 6: 139-146.

Ximei DAI, Qunce HUANG, Guoping LI, Xiuming HU, Guangyong QIN and Zengliang YU (2006) Study of genetics and embryology of polyembryonic mutant of autotetraploid rice induced by $\mathrm{N}+$ beam implantation. Plasma Science \& Technology 8(6): 745-750.

Ye S, Yang W, Zhai R, Lu Y, Wang J and Zhang X (2017) Mapping and application of the twingrain1 gene in rice. Planta 245: 707-716.

Yoshida H and Nagato Y (2011) Flower development in rice. J. Exp. Bot. 62: 4719-30.

(Manuscript received on 4 December, 2021; revised on 15 December, 2021) 